\title{
Review Article \\ Influence of Nanofinishes on the Antimicrobial Properties of Fabrics
}

\author{
N. Gokarneshan, P. P. Gopalakrishnan, and B. Jeyanthi \\ NIFT TEA College of Knitwear Fashion, Tirupur 641 606, India \\ Correspondence should be addressed to N. Gokarneshan, advaitcbe@rediffmail.com \\ Received 20 September 2012; Accepted 12 November 2012 \\ Academic Editors: A. Fidalgo, A. A. Ismail, and A. Kelarakis
}

Copyright ( $) 2012$ N. Gokarneshan et al. This is an open access article distributed under the Creative Commons Attribution License, which permits unrestricted use, distribution, and reproduction in any medium, provided the original work is properly cited.

This paper critically reviews the influence of the various types of nanomaterials on the antibacterial property of the treated fabrics. The merits of each type of nanomaterial have been compared. The synthesis and application method of each type are highlighted. As the number of microorganisms is growing increasingly resistant to antibiotics, the need to treat fabrics with nano materials becomes important in order to improve the antibacterial efficacy over a range of bacterium and fungi. The various researches reported herein show a promise for wider applications in medical textiles. Nano finishes have been applied on natural materials such as cotton, wool, and silk and also synthetic materials such as PET fabrics, with interesting results.

\section{Introduction}

Textile materials tend to act as a good medium for the growth and multiplication of microorganisms. The basic chemical constituents present in the natural fibers provide nutrition to microorganisms and thereby promote their growth. The growth of microorganisms in the textile materials cause innumerable problems such as unacceptable odor, loss of strength in fabric, and stains and, moreover, affect the health of the wearer. It is therefore important to impart antimicrobial effect on textile materials so as to protect the health of the wearer. A number of antimicrobial agents have been used in textile applications [1]. Of these silver nanoparticles have one of the best antimicrobial characteristics and cover a wide range of pathogenic microorganisms. They react with the sulfur-based proteins of the cell wall in microorganisms, inhibit with their metabolism, and thereby destroy them $[2,3]$. Cotton, wool, and silk fabrics have been effectively treated with silver nanoparticles to get the desired antimicrobial efficts [4-6]. However, the use of silver nanoparticles in textile applications has its own restrictions, as particle size below $50 \mathrm{~nm}$ can have a harmful impact on humans and the environment $[7,8]$. Inorganic materials such as metal and metal oxides have attracted lots of attention over the past decade due to their ability to withstand harsh process conditions $[9,10]$. Of the inorganic materials, metal oxides such as $\mathrm{TiO}_{2}, \mathrm{ZnO}, \mathrm{MgO}$, and $\mathrm{CaO}$ are of a particular interest as they are not only stable under harsh process conditions but also generally regarded as safe materials to human beings and animals [11]. The use of nanoparticles of silver and zinc oxide has been seen as a viable solution to stop infectious diseases due to the antimicrobial properties of these nanoparticles. The intrinsic properties of a metal nanoparticle are mainly determined by size, shape, composition, crystallinity, and morphology [12]. With growth in world population and the spread of disease, the number of antibiotic resistant microorganisms is rising along with the occurrence of infections from these microorganisms. With this increase in health awareness, many people focused their attention on educating and protecting themselves against harmful pathogens. It soon became more important for antimicrobially finished textiles to protect the wearer from bacteria than it was to simply protect the garment from fiber degradation [13]. The need for antimicrobial textiles goes hand-in-hand with the rise in resistant strains of microorganisms. 


\section{Finishes on Natural Fibres and Blends}

\subsection{Finish with Titanium Oxide}

2.1.1. Synthesis of Titanium Oxide. In one of the methods reported [14], titanium tetrachloride has been used, which has been gradually added onto distilled water, four times its volume, maintained at ice cool temperature, and then taken to room temperature. Stirring has been done for 30 minutes to get a homogenous solution. The temperature of the bath has been raised to $150^{\circ} \mathrm{C}$ and maintained till the process of nanoparticle has been completed. Also urea has been dissolved in distilled water in the ratio of $1: 12$. The urea solution so prepared has been added to the previously prepared solution under constant stirring. The solution changed into a white colloid without any precipitation. When the reaction has been completed, the solution was allowed to settle and washed five times with distilled water.

2.1.2. Method of Application. Woven and knitted fabric comprising of $100 \%$ cotton and polyester/cotton (45/55) has been applied with titanium dioxide nanoparticles by spraying, using the pad dry cure method. The nanoparticles have been applied on the face side of the fabric with $1 \%$ concentration and material liquor ratio of $1: 20$ and $1 \%$ acrylic binder. Fabrics comprising of $100 \%$ cotton as well as $45 / 55 \%$ polyester/cotton produced as woven and knits have been coated with titanium dioxide nanoparticles in a dispersion form by using a spray gun. The fabric substrate has been fixed on a vertical board and nanoparticle solution evenly sprayed over the fabric by using a spray gun. A constant distance has been maintained between the fabric and spray gun nozzle. A padding mangle running at a speed of $15 \mathrm{~m} / \mathrm{min}$ and with pressure of $15 \mathrm{kgs} / \mathrm{cm}^{2}$ has been used to squeeze out the excess solution [16]. The fabrics have then been dried naturally and cured for $3 \mathrm{~min}$ at $150^{\circ} \mathrm{C}$.

2.1.3. Influence on Antibacterial Property. The coating of titanium dioxide in nanoform on the fabric surface enables improvement in the antimicrobial, UV blocking, and selfcleaning properties [2]. Nanotitanium dioxide solution and finishing agent have been prepared by sol-gel method. In this method of preparation tetrabutyl titanate have been used as the precursor and ethanol as the solvent. A padding technique has been adopted to impregnate polyester fabric with the agent [16]. Investigations for antimicrobial activity has been carried out on $100 \%$ cotton and polyester/cotton (45/55) woven and knitted fabrics. Titanium dioxide have normally been preferred over other titanium compounds owing to its higher effectiveness in preventing infections. The treated fabrics showed the growth of both types of organisms, namely, Staphylococcus aureus and Klebseilla pneumoniae. The growth of the bacteria has been found on both the fabric as well as surrounding it. In the case of titanium dioxide treated fabric, no bacterial growth has been observed on the fabric, but was surrounding it. Treated woven fabrics exhibit better bacterial reduction than their knitted counterpart, due to their construction. The blended fabric having 45/55 polyester/cotton exhibits better bacterial reduction than
TABLE 1: Antibacterial activity of titanium dioxide nanoparticles treated fabrics [14].

\begin{tabular}{lcc}
\hline Fabric samples & $\begin{array}{c}\text { Staphylococcus } \\
\text { aureus }\end{array}$ & $\begin{array}{c}\text { Klebsiella } \\
\text { pneunomiae }\end{array}$ \\
\hline Untreated & No reduction & No reduction \\
Woven 100\% cotton & $85 \%$ & $64 \%$ \\
Woven 45/55 polyester/cotton & $93 \%$ & $78 \%$ \\
Knitted 100\% cotton & $75 \%$ & $58 \%$ \\
Knitted 45/55\% polyester cotton & $79 \%$ & $74 \%$ \\
\hline
\end{tabular}

$100 \%$ cotton due to the resistance property of polyester (Table 1).

\subsection{Finish with Zinc Oxide}

2.2.1. Method of Synthesis. The zinc oxide nanoparticles have been synthesized by two methods. The synthesis involved the use of zinc chloride, caustic soda (in pellet form), ethanediol, and propanol [17].The synthesis has been done under a state of very high saturation in such a way that the rate of nucleation achieved has been far higher than the growth rate [18]. Zinc chloride has been dissolved in $200 \mathrm{~mL}$ of water by maintaining a temperature of $90^{\circ} \mathrm{C}$ in an oil bath. Subsequently caustic aqueous solution has been added to zinc chloride solution with mild stirring for a period of about 10 minutes maintaining temperature at $90^{\circ} \mathrm{C}$. Sedimentation technique has been adopted to isolate the particles from the supernatant dispersion.

The supernatant solution has been dispensed with and the suspension that remained has been washed with distilled water five times so as to reduce the concentration of sodium chloride below $10^{-6}$ mole $(\mathrm{M})$. The dilution ratio between the concentrated suspension and the washing solution has been kept at $1: 10$, during every wash. The complete removal of the sodium chloride from the suspension was checked using the solution of silver nitrate. The purified particles were then peptized with 2-propanol in an ultrasonic bath for $10 \mathrm{~min}$ at room temperature. The peptization process is necessary to disrupt the microagglomerates and to release the nano particles of zinc oxide [19]. The particles were then collected by centrifugation at $6000 \mathrm{rpm}$ for $15 \mathrm{~min}$. The washing procedure was repeated three times. Thermal treatment of the particles at $250^{\circ} \mathrm{C}$ for 5 hours leads to the formation of zinc oxide. This method of synthesis of zinc oxide nano particles using water medium is for synthesis 1 . In the second method of synthesis zinc oxide nano particles were synthesized using 1,2-ethanediol (instead of water) medium at $150^{\circ} \mathrm{C}$ keeping all other parameters same as described in synthesis 1 .

In another research work [13], zinc oxide nano particles have been synthesized by the use of zinc nitrate and sodium hydroxide (precursors) and soluble starch (stabilizing agent) by adopting the wet chemical method. Soluble starch in varying concentrations $(0.1 \%, 0.5 \%$, and $1.0 \%)$ has been dissolved by $500 \mathrm{~mL}$ of distilled water, in a microwave oven. Zinc nitrate in suitable proportion has been added with 
constant stirring, so as to completely dissolve it in the solution. Sodium hydroxide solution of $0.2 \mathrm{M}$ has then been added under constant stirring in a dropwise manner. After the complete addition of sodium hydroxide, the reaction was allowed to proceed for two hours. The solution has been allowed to settle overnight and the supernatant solution then discarded carefully. The remaining solution has been centrifuged and the nano particles so obtained have been washed with distilled water thrice. The washed nano particles have then been dried at $80^{\circ} \mathrm{C}$ overnight, resulting in a complete conversion of zinc hydroxide into zinc oxide [20].

2.2.2. Method of Application. Four types of fabrics have been produced using $100 \%$ cotton as well as $45 / 55$ polyester/cotton in the form of knits and woven fabrics. These have been dyed using reactive blue dyes under identical conditions. The fabrics have been conditioned at $21^{\circ} \mathrm{C}$ and $65 \% \mathrm{RH}$ and then soaked for 10 minutes in 2-propanol dispersion zinc oxide nano particles $(5 \% \mathrm{w} / \mathrm{w})$ under gentle magnetic stirring. The fabrics then have been squeezed on a padding mangle and oven-dried at $130^{\circ} \mathrm{C}$ for $15 \mathrm{~min}$ at an atmospheric pressure. The treated fabrics have then been washed five times as per the method described (UNI EN ISO 26330:1996). Laundering has been done and the washing cycles performed at $30^{\circ} \mathrm{C}$ with reference detergent without optical brighteners. The drying has been done on a flat surface, and the fabrics were tested before and after washing cycles using TEM and UV spectrophotometry in order to characterize the size and shape of the nano particles deposited.

2.2.3. Influence on Antibacterial Property. Qualitative antibacterial evaluation by agar diffusion method has shown that $100 \%$ cotton woven fabrics treated with zinc oxide nanoparticles showed a maximum inhibitory effect against S. aureus [21]. The results are indicative that $\mathrm{ZnO}$ treated fabric exhibits a higher antibacterial activity in comparison with $\mathrm{ZnO}$ bulk treated fabrics, while the untreated fabrics exhibited no antibacterial activity. The antibacterial activity has been observed to be higher in the case of $S$. aureus than E. coli, for both the fabrics treated with $\mathrm{ZnO}$ nanoparticles as well as the bulk treated ones, in all the trials carried out. Earlier study [21] seems to indicate that active oxygen species generated by $\mathrm{ZnO}$ particles could be a mechanism although there is no direct evidence from the reported study. A study has revealed the presence of active oxygen species [22]. It has already been proved that nanosized and micro sized $\mathrm{ZnO}$ suspensions are active in inhibiting the growth of bacteria. The nanosized $\mathrm{ZnO}$ suspension clearly has a much higher activity than the microsized $\mathrm{ZnO}$ suspension [22]. These results correlated with the subsequent investigation [21], as in both cases, that is, $\mathrm{ZnO}$ particle treated fabrics and bulk treated fabrics, exhibited an antibacterial activity. However, the $\mathrm{ZnO}$ nanoparticle treated fabrics showed a much higher antibacterial activity than its counterpart. Antimicrobial evaluation by parallel streak method revealed that $\mathrm{ZnO}$ nanoparticle treated fabric exhibited a maximum inhibitory effect against $S$. aureus with a zone of inhibition of $5.8 \mathrm{~cm}$
TABLe 2: Agar diffusion test for treated and washed cotton fabrics [4].

\begin{tabular}{lccc}
\hline \multirow{2}{*}{ Samples } & \multicolumn{3}{c}{ Zone of inhibition* } \\
& S. aureus & E. coli & P. aeruginosa \\
\hline Control & Nil & Nil & Nil \\
Silver nanopowder treated & & & \\
$\quad$ Without washing & 38 & 41 & 37 \\
After 5 washes & 37 & 40 & 35 \\
After 10 washes & 37 & 40 & 35 \\
After 20 washes & 35 & 38 & 35 \\
\hline
\end{tabular}

* Diameter of the control sample is $20 \mathrm{~mm}$.

followed by E. coli, with a zone of inhibition of $3.7 \mathrm{cms}$. The percentage reduction test has been used to investigate the bacterial reduction quantitatively (Table 2 ). The results of this test correspond with those of the other methods, namely, the agar diffusion and parallel streak method. The $\mathrm{ZnO}$ nanoparticle treated fabrics exhibit a reduction percentage of $94.16 \%$ for S. aureus followed by $86.5 \%$ for E. coli. On the other hand the $\mathrm{ZnO}$ bulk treated fabrics exhibit comparatively a lower reduction percentage, while the untreated fabrics have negative values for the percentage reduction as the final number of bacterial cells will be much higher than the initial number, since it will have no bactericidal activity reflecting zero result. The improved bioactivity of $\mathrm{ZnO}$ nanoparticles has been investigated by researchers and its antimicrobial activity has been evaluated [23] and their antibacterial activity has been established. SEM observations have revealed that the $\mathrm{ZnO}$ particles produced by the wet chemical method are almost spherical, the particle size between 60 and $75 \mathrm{~nm}$. SEM photographs have revealed that the treated fabrics show $\mathrm{ZnO}$ nanoparticles embedded onto fabrics. Tests on wash durability have shown that a considerable antimicrobial activity has been considerably retained in the $\mathrm{ZnO}$ nanoparticles treated fabrics up to 10 washes even after repeated wash cycles. The extent of bacterial reduction has been very low after 10 washes, and after 20 wash there has been no activity. In the case of $\mathrm{ZnO}$ bulk treated fabrics, the antibacterial activity has been retained only upto 5 repeated wash cycles.

A number of methods are available for the preparation of $\mathrm{ZnO}$ powder [24-28]. The nanoparticle size differs with each method $(60-100 \mathrm{~nm})$ and is influenced by parameters such as precursor type, solvent, $\mathrm{pH}$, and the temperature of reacting solution. The choice of method depends on the final application. The improved bioactivity of the smaller $\mathrm{ZnO}$ nanoparticles is due to the higher surface area to volume ratio. For smaller $\mathrm{ZnO}$ nanoparticles, more particles are needed to cover a bacterial colony $(2 \mu \mathrm{m})$ which results in the generation of a larger number of active oxygen species (released from $\mathrm{ZnO}$ on the surface of the colony), which kill bacteria more effectively. $\mathrm{ZnO}$ nanoparticles were found to be more abrasive than bulk $\mathrm{ZnO}$ and thus contribute to the greater mechanical damage of the cell membrane and the enhanced bactericidal effect of $\mathrm{ZnO}$ nanoparticles. 


\subsection{Finish with Silver Oxide}

2.3.1. Method of Synthesis. In a recent research [29], silver nanoparticles have been synthesized by adopting sonochemical method. The solution has been prepared in deionized water. Silver nitrate solution of $1 \times 10^{-3} \mathrm{M}$ containing $2 \%$ Poly vinyl Pyrrolidone has been sonicated in an ultra sonicator for a duration of 3 hours. The sonicated solution has then been boiled and 1\% trisodium citrate has been added subsequently in a dropwise manner, until the color of the solution changed to yellow. The formation of silver nanoparticles is indicated by the yellow color of the solution. The silver nanoparticles obtained in the solution form have then been converted as powder $(50-60 \mathrm{~nm})$ by means of spray drying.

2.3.2. Method of Application. The silver nanoparticles that have been converted to powder have been dissolved in water so as to achieve a concentration of $50 \mathrm{ppm}$ silver content. This has been applied on cotton and wool fabrics by exhaustion method. The fabrics have then been treated for 45 minutes at boiling temperature and then washed with normal water. The durability of the treated fabrics has been assessed according to AATCC 124-2001 procedure, for 5, 10, and 20 washes. The antimicrobial effect of the treated wool and cotton fabrics has been evaluated qualitatively by the agar diffusion method and quantitatively by the AATCC 100 [30].

2.3.3. Influence on Antibacterial Property. The results of the agar diffusion test for the assessment of antimicrobial efficacy for treated cotton fabrics as well as varyingly washed fabrics with regard to the inhibition zone are shown in Table 2 [30]. The results show a clear zone of inhibition ranging between 35 and $40 \mathrm{~mm}$ diameter for the fabrics treated against the selected microorganisms. Even after 20 washes the zone of inhibition remains visible in the fabrics so treated. The quantitative test results for the evaluation of antimicrobial efficacy of treated wool fabrics are shown in Table 2. It could be observed that the treated wool fabrics exhibit 100\%, 97\%, and 99\% efficacy against S. aureus, E. coli and $P$. aeruginosa, respectively. The antimicrobial efficacy has been observed even after 20 washes in the treated fabrics. The PVP in the nanosilver powder forms hydrogen bond with hydroxyl groups of the cotton and the wool and also forms a coordinate bond with the silver nanoparticles and thereby enhances the durability of the antimicrobial finish. The PVP coated silver nanoparticles offer advantages such as the durability of finish and operational benefits that include simple handling, ease of application, and avoidance of agglomeration of nanoparticles.

Silver nanoparticles have been applied on silk fabrics [4]. The nanoparticles have been produced using a chemical method by reducing silver nitrate with reducing agents such as hydrazine and glucose. Silk fabric has been treated with silver nitrate in acidic pH between 3 and 4. Good antimicrobial activity has been observed against $S$. aureus and the fabrics have been maintained up to $80 \%$ antimicrobial
TABLE 3: Evaluation of antimicrobial activity for fabrics treated with nanosilver [15].

\begin{tabular}{lcc}
\hline Fabric type & $\begin{array}{c}\text { Growth of S. aureus } \\
\text { under specimen }\end{array}$ & $\begin{array}{c}\text { Zone of inhibition } \\
\text { S. aureus }(\mathrm{mm})\end{array}$ \\
\hline $\begin{array}{l}\text { SILPURE-treated cotton } \\
\text { fabric }\end{array}$ & No & 1.66 \\
$\begin{array}{l}\text { Meso silver-treated } \\
\text { cotton fabric }\end{array}$ & No & 1.21 \\
Untreated cotton fabric & Yes & 0 \\
\hline
\end{tabular}

activities after 5 cycles of washing. In yet another interesting recent work [31], antimicrobial activities have been observed on cotton fabrics by applying meso silver particles and silver chloride compounds (SILPURE). Evaluation has been done on the antibacterial assessment with treated as well as untreated fabrics. The zone of inhibition has been considered and the bacterial growth has been assessed as shown in Table 3.

\subsection{Finish with Silver Nanocolloids}

2.4.1. Method of Synthesis. A measured amount of silver sulphate $\left(1 \times 10^{-3} \mathrm{M}\right)$ solution has been kept in a specially designed reaction chamber. The solution has then been reduced by the addition of cold and dilute solution of sodium borohydride in a nitrogen atmosphere, in a dropwise manner [15]. The mixture of the solution has been vigorously stirred during the reaction process. As the solution colour turned to light yellow, a small amount of trisodium citrate (1\%) has been added dropwise with vigorous stirring. Distilled water has been used for preparing the solutions. The reaction equation is chemically represented below

$$
\begin{gathered}
4 \mathrm{Ag}^{+2}+\mathrm{NaBH}_{4}+2 \mathrm{H}_{2} \mathrm{O} \longrightarrow 4 \mathrm{Ag}+\mathrm{BH}_{4} \\
+\mathrm{Na}^{+}+4 \mathrm{H}^{+}+\mathrm{O}_{2}
\end{gathered}
$$

2.4.2. Method of Application. Silver nanoparticles have been applied onto cotton, wool, and silk fabrics by dipping them in the dispersion for a duration of 10 minutes [15]. The fabrics have then been padded adopting a double dip and nip sequence at $70 \%$ expression. The padded fabrics have then been dried in air and cured at $120^{\circ} \mathrm{C}$ for 20 minutes.

2.4.3. Influence on Antibacterial Property. The antibacterial efficacy of the untreated as well as treated fabrics has been evaluated by measuring the loss in breaking load due to soil burial test (Figure 1) [15]. The results show that the treated fabrics exhibit the reduction of loss in breaking load in the case of cotton, wool, and silk fabrics. This indicates that treatment with silver nanocolloids improves the bacterial resistance in the treated fabrics. It could be attributed to the metallic ions and metallic compounds exhibiting a certain degree of a sterilizing effect. The oxygen present in the atmosphere is partially converted to active oxygen due to catalysis with the metallic ion and thus dissolves the organic substance to produce a sterilizing effect [32]. 


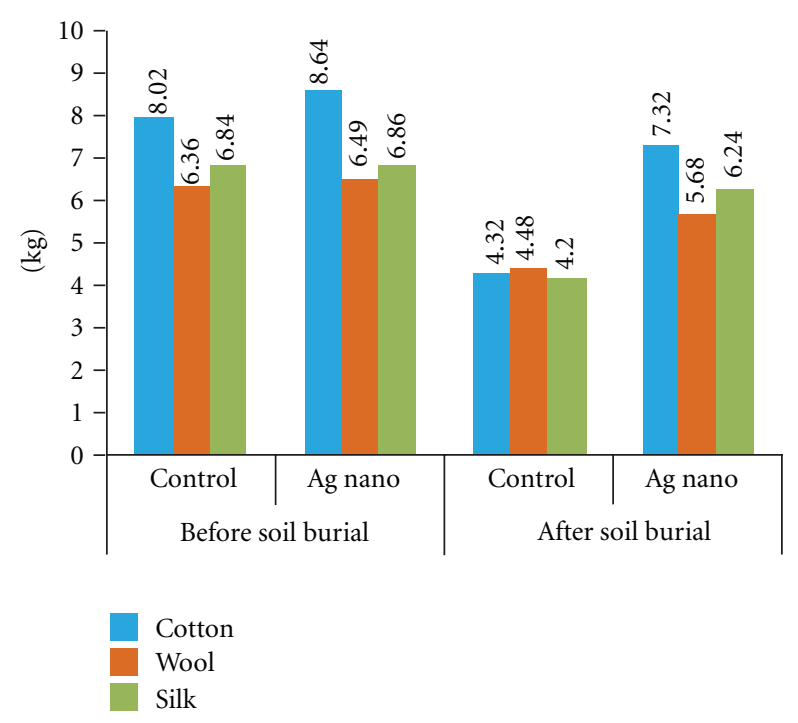

Figure 1: Effect of silver nanoparticles on resistance towards bacterial attack [32].

The antibacterial effect is greatly improved on account of the very large relative surface area, increasing their contact with bacteria or fungi. Nano silver has been found to be highly reactive with proteins. It therefore interferes with cell growth by seriously affecting cellular metabolism, through its contact with bacteria or fungus. Moreover, the respiration, basal metabolism of the electron system, and the transport of substrate in the microbial cell membrane get suppressed by the nanosilver particles. They also prevent the growth and division of bacteria and fungi that cause infection, odour, itchiness, and sores.

\section{Finishes on Synthetic Fibres}

\subsection{Finish on Polyethylene Terephthalate (PET)}

3.1.1. Method of Preparation and Application. PET fabrics have been subjected to single- and double-sided corona air treatment at the atmospheric pressure using a device meant for the purpose [34]. Fabrics have been placed on a backing electrode roller covered with silicon coating and rotating at a speed of $4 \mathrm{~m} / \mathrm{min}$. The distance between electrodes has been maintained at $2 \mathrm{~mm}$. Corona plasma has been generated in the gap between the electrode and backing roller. Blank dyed fabrics with nano silver particles have been tested for bacterial reduction as per ASTM-E 2149-01 method [35]. The percentage reduction of the organisms resulting from contact with the specimen has been calculated. Corona plasma treatment has been used for the preparation of surfaces of PET fabrics so as to obtain better adhesive properties to nano silver particles. Nano silver particles of size $80 \mathrm{~nm}$ have been used.

3.1.2. Influence on Antibacterial Properties. Raw, washed, and washed-thermostabilized fabrics have been tested for antimicrobial efficacy. The microbial reduction is based on the concentration of the nanosilver in the case of raw plasma treated fabrics [34]. These fabrics exhibit the highest adsorption of silver. The increase adsorption of nanosilver in the case of raw plasma treated fabrics can be attributed by the increase in the surface area and a change in the surface composition and chemical bonding resulting from the corona air plasma treatment. The raw fabrics become more porous and seem to be conducive for silver absorption. Thus the raw plasma treated fabrics exhibit the highest adsorption of silver in comparison to washed and washed-thermostabilized fabrics and therefore give the best microbial reduction. The bacterial cultures examined are Staphylococcus aureus, Escherichia coli, Streptococcus faecalis, Pseudomonas aeruginosa. Of these, Staphylococcus aureus and Streptococcus faecalis show a significant reduction of more than $60 \%$ of the treated PET fabrics. The long-term changes of fabric surfaces obtained by plasma treatment can hold good promise for industrial applications.

In another work $[33,36]$, two types of bacteria, namely, Staphylococcus aureus, Escherichia coli, have been used to assess the antibacterial activity of PET fabrics finished with nanometer titanium dioxide/nanometer silver/water borne polyurethane composite emulsion. The antibacterial activity of the standard as well as the treated fabrics (mixture of nano- $\mathrm{TiO}_{2}$ and nano-Ag) is shown in Figures 2(a) and 2(c), against S. aureus. Figures 2(b) and 2(d) exhibit the antibacterial activity in the case of $E$. coli. In both cases the test fabrics have been irradiated with UV light for 6 hours prior to evaluation. Figures 2(c) and 2(d) clearly indicate that the fabrics treated with the mixture of nano- $\mathrm{TiO}_{2}$ and nano-Ag particle exhibit a higher level of antibacterial activity, but the standard samples shown in Figures 2(a) and 2(b) exhibited little or no antibacterial activity. The comparative figures reveal that the circle in the middle area is the fabric sample and the curvimaterials are the bacteria on the standard bacterial liquid. The curvimaterial in Figures 2(a) and 2(c) on the circular area is continuous and clear. This phenomenon indicates that the antibacterial activity of the standard fabric is almost ineffective. The curvimaterial in Figures 2(b) and 2(d) is disappearing. This shows that in the case of the treated fabric, the antibacterial agent has destroyed the bacteria and thus rendered the fabric significantly effective. It could also be visualized that the UV light irradiation before antibacterial testing could photosensitize the nano- $\mathrm{TiO}_{2} /$ nano-Ag to destroy the bacteria.

\section{Conclusion}

Nano finishes have been applied onto fabrics for the attainment of desirable functional properties. Of these, the antimicrobial property has been one of the most prominent and promising. Recent research findings in the area of antimicrobial finishes have been reviewed in this paper. Important nanomaterials used include titanium dioxide, zinc oxide, silver oxide, and silver nanocolloids. Each type of nanomaterial applied on fabrics has been analyzed for specific bacterium cultures. In the case of nanotitanium dioxide, the bacterial cultures examined were Staphylococcus aureus and Klebseilla 


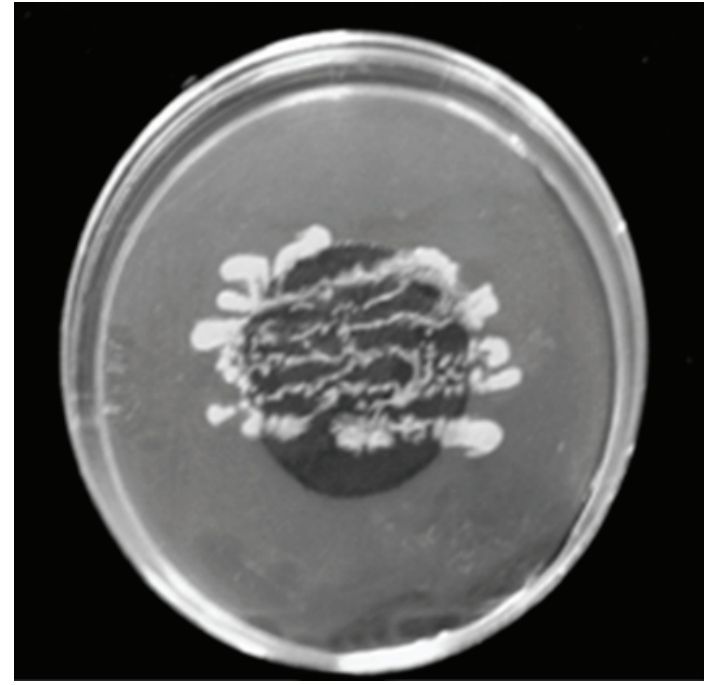

(a)

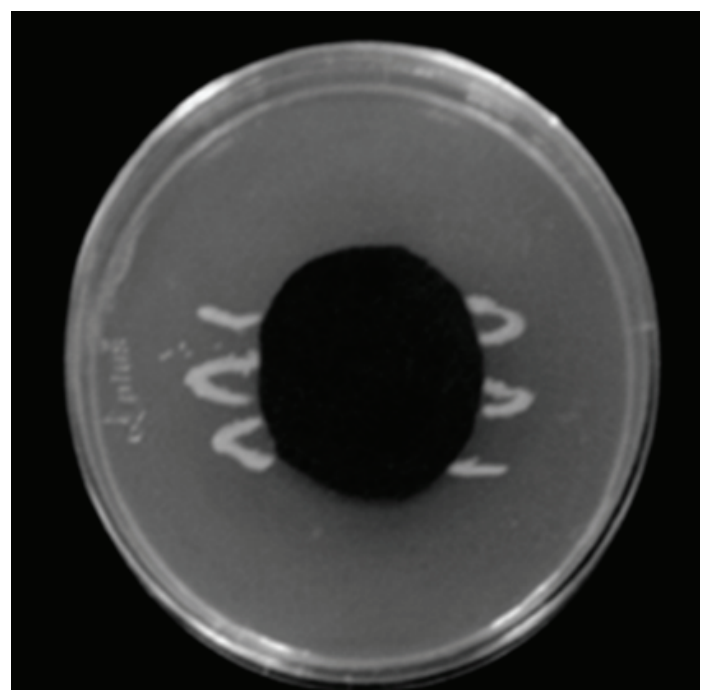

(c)

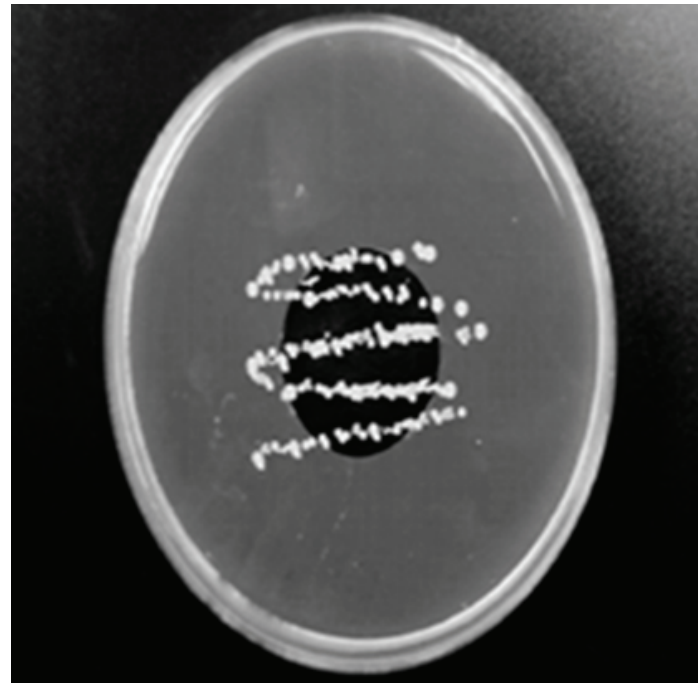

(b)

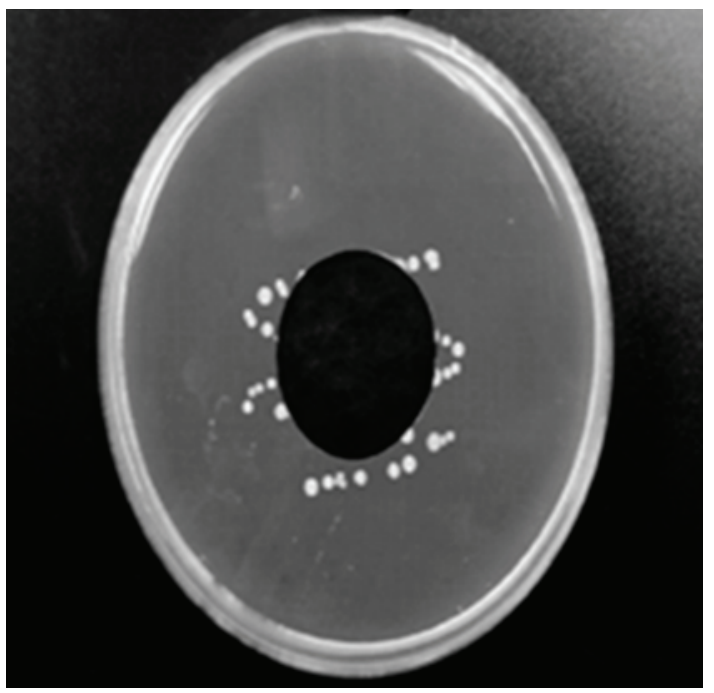

(d)

FIGURE 2: Antibacterial activity for ((a) and (c)) S. aureus and ((b) and (d)) E. coli. (a) and (c): control samples; (b) and (d): fabric samples finished with mixed nano- $\mathrm{TiO}_{2} /$ nano- $\mathrm{Ag}(2.0 \mathrm{wt} \% / 125 \mathrm{ppm})$ [33].

pnrumoniae. Nanotitanium dioxide has been applied on $100 \%$ cotton and 45/55 cotton/polyester blend fabric. In the case of blend fabric, the polyester component exhibited better microbial reduction than its cotton counterpart. Zinc oxide nanoparticles have been applied on cotton fabrics. Antimicrobial evaluation by different methods has proved that a higher antimicrobial activity has been observed in the case of bacterium S. aureus than E. coli. Silver nanoparticles have been applied on wool and silk fabrics. The bacterium observed were S. aureus, E. coli and P. aeruginosa. The antimicrobial efficacy has been observed even after 20 washes in the treated fabrics. Nano silver colloids have been applied onto cotton, silk, and wool fabrics. The sterilizing effect produced by the silver ions and compounds contributed to the antimicrobial efficacy. Besides being applied on natural materials such as cotton, wool, and silk fabrics, nano finishes have also been applied onto PET fabrics. In one case fabrics have been treated with air plasma. Raw plasma treated fabrics have shown the best adsorption of silver as compared to washed and washed-thermostabilized fabrics and hence give the best antimicrobial efficacy. In another case PET fabrics have been treated with nanometer titanium dioxide/nanometer silver/water borne polyurethane composite emulsion and have shown a good antimicrobial efficacy. The foregoing discussions clearly point out that various types of nanomaterials applied to fabrics produce good antimicrobial effects, which are considered even better than antibiotic effects. The researches on the antimicrobial treatment of textiles clearly hold promise in medical applications in the near future. However, the impact of the different nanomaterials on the human health and environment needs to be well researched and established before they gain a commercial acceptance. 


\section{References}

[1] Y. Gao and R. Cranston, "Recent advances in antimicrobial treatments of textiles," Textile Research Journal, vol. 78, no. 1, pp. 60-72, 2008.

[2] H. J. Lee and S. H. Jeong, "Bacteriostasis and skin innoxiousness of nanosize silver colloids on textile fabrics," Textile Research Journal, vol. 75, pp. 551-556, 2005.

[3] H. Y. Ki, J. H. Kim, S. C. Kwon, and S. H. Jeong, "A study on multifunctional wool textiles treated with nano-sized silver," Journal of Materials Science, vol. 42, pp. 8020-8024, 2000.

[4] M. L. Gulrajani, D. Gupta, S. Periyasamy, and S. G. Muthu, "Preparation and application of silver nanoparticles on silk for imparting antimicrobial properties," Journal of Applied Polymer Science, vol. 108, no. 1, pp. 614-623, 2008.

[5] N. Vigneshwaran, A. A. Kathe, P. V. Varadarajan, R. P. Nachane, and R. H. Balasubramanya, "Functional finishing of cotton fabrics using silver nanoparticles," Journal of Nanoscience and Nanotechnology, vol. 7, no. 6, pp. 1893-1897, 2007.

[6] E. Falletta, M. Bonini, E. Fratini et al., "Clusters of poly(acrylates) and silver nanoparticles: Structure and applications for antimicrobial fabrics," Journal of Physical Chemistry C, vol. 112, no. 31, pp. 11758-11766, 2008.

[7] M. K. Yeo and M. Kang, "Effects of nanometer sized silver materials on biological toxicity during zebrafish embryogenesis," Bulletin of the Korean Chemical Society, vol. 29, pp. 11791184, 2008.

[8] P. Nagendar Reddy, E. M. Pena-Mendez, and J. Havel, "Silver or silver nanoparticles: a hazardous threat to the environment and human health? " Journal of Applied Biomedicine, vol. 6, pp. 117-119, 2008.

[9] L. Fu, Z. Liu, Y. Liu et al., "Beaded cobalt oxide nanoparticles along carbon nanotubes: Towards more highly integrated electronic devices," Advanced Materials, vol. 17, no. 2, pp. 217 221, 2005.

[10] S. Makhluf, R. Dror, Y. Nitzan, Y. Abramovich, R. Jelinek, and A. Gedanken, "Microwave-assisted synthesis of nanocrystalline $\mathrm{MgO}$ and its use as a bacteriocide," Advanced Functional Materials, vol. 15, no. 10, pp. 1708-1715, 2005.

[11] P. K. Stoimenov, R. L. Klinger, G. L. Marchin, and K. J. Klabunde, "Metal oxide nanoparticles as bactericidal agents," Langmuir, vol. 18, no. 17, pp. 6679-6686, 2002.

[12] R. M. Dickson and L. A. Lyon, "Unidirectional plasmon propagation in metallic nanowires," Journal of Physical Chemistry B, vol. 104, no. 26, pp. 6095-6098, 2000.

[13] A. Yadav, V. Prasad, A. A. Kathe et al., "Functional finishing in cotton fabrics using zinc oxide nanoparticles," Bulletin of Materials Science, vol. 29, no. 6, pp. 641-645, 2006.

[14] V. Parthasarathi and G. Thilagavathi, "Synthesis and characterization of titanium dioxide nano-particles and their applications to textiles for microbe resistance," Journal of Textile and Apparel, Technology and Management, vol. 6, no. 2, 2009.

[15] D. P. Chattopadhyay and B. H. Patel, "Improvement in physical and dyeing properties of natural fibres through pretreatment with silver nanoparticles," Indian Journal of Fibre and Textile Research, vol. 34, no. 4, pp. 368-373, 2009.

[16] L. Haixia, D. Hua, and Z. Jing, "Performance research of polyester fabric treated by nano titanium dioxide $(\mathrm{N}$ ano-TiO2) anti-ultraviolet finishing," International Journal of Chemistry, vol. 1, p. 57, 2009.
[17] S. Kathirvelu, L. D’Souza, and B. Dhurai, "UV protection finishing of textiles using $\mathrm{ZnO}$ nanoparticles," Indian Journal of Fibre and Textile Research, vol. 34, no. 3, pp. 267-273, 2009.

[18] M. Moroni, D. Borrini, L. Calamai, and L. Dei, "Ceramic nanomaterials from aqueous and 1,2-ethanediol supersaturated solutions at high temperature," Journal of Colloid and Interface Science, vol. 286, no. 2, pp. 543-550, 2005.

[19] Y. J. Kwon, K. H. Kim, C. S. Lim, and K. B. Shim, "Characterization of $\mathrm{ZnO}$ nanopowders synthesized by the polymerized complex method via an organochemical route," Journal of Ceramic Processing Research, vol. 3, no. 3, pp. 146-149, 2002.

[20] R. Rajendran, C. Balakumar, M. A. Hasabo, S. Jayakumar, K. Vaideki, and E. M. Rajesh, "Use of zinc oxide nano particles for production of antimicrobial textiles," International Journal of Engineering, Science and Technology, vol. 2, no. 1, pp. 202208, 2010.

[21] L. Zhang, Y. Jiang, Y. Ding et al., Journal of Nanoparticle Research, vol. 10, pp. 9711-9711, 2009.

[22] O. Yamamoto, J. Sawai, and T. Sasamoto, "Change in antibacterial characteristics with doping amount of $\mathrm{ZnO}$ in $\mathrm{MgO}-\mathrm{ZnO}$ solid solution," International Journal of Inorganic Materials, vol. 2, no. 5, pp. 451-454, 2000.

[23] N. Padmavathy and R. Vijayaraghavan, "Enhanced bioactivity of $\mathrm{ZnO}$ nanoparticles - an antimicrobial study," Science and Technology of Advanced Materials, vol. 9, no. 3, Article ID 035004, 2008.

[24] T. Q. Liu, O. Sakurai, N. Mizutani, and M. Kato, "Preparation of spherical fine $\mathrm{ZnO}$ particles by the spray pyrolysis method using ultrasonic atomization techniques," Journal of Materials Science, vol. 21, no. 10, pp. 3698-3702, 1986.

[25] T. Trindade, J. D. Pedrosa De Jesus, and P. O’Brien, "Preparation of zinc oxide and zinc sulfide powders by controlled precipitation from aqueous solution," Journal of Materials Chemistry, vol. 4, no. 10, pp. 1611-1617, 1994.

[26] M. A. Vergés and M. M. Gallego, "Spherical and rodlike zinc oxide microcrystals: morphological characterization and microstructural evolution with temperature," Journal of Materials Science, vol. 27, no. 14, pp. 3756-3762, 1992.

[27] D. Chen, X. Jiao, and G. Cheng, "Hydrothermal synthesis of zinc oxide powders with different morphologies," Solid State Communications, vol. 113, no. 6, pp. 363-366, 2000.

[28] S. Mahamuni, K. Borgohain, B. S. Bendre, V. J. Leppert, and S. H. Risbud, "Spectroscopic and structural characterization of electrochemically grown $\mathrm{ZnO}$ quantum dots," Journal of Applied Physics, vol. 85, no. 5, pp. 2861-2865, 1999.

[29] A. S. M. Raja, G. Thilagavathi, and T. Kannaian, "Synthesis of spray dried polyvinyl pyrrolidone coated silver nanopowder and its application on wool and cotton for microbial resistance," Indian Journal of Fibre and Textile Research, vol. 35, no. 1, pp. 59-64, 2010.

[30] G. Thilagavathi, K. Rajendrakumar, and R. Rajendran, "Development of ecofriendly antimicrobial textile finishes using herbs," Indian Journal of Fibre and Textile Research, vol. 30, no. 4, pp. 431-436, 2005.

[31] S. Ghosh, S. Yadav, and N. Reynolds, "Antibacterial properties of cotton fabric treated with silver nanoparticles," Journal of the Textile Institute, vol. 101, no. 10, pp. 917-924, 2010.

[32] M. Saito, "Antibacterial, deodorizing, and UV absorbing materials obtained with zinc oxide $(\mathrm{ZnO})$ coated fabrics," Journal of Coated Fabrics, vol. 23, pp. 150-164, 1993.

[33] N. Gokarneshan, P. P. Gopalakrishnan, and B. Jeyanthi, "Influence of various nano finishes on the functional properties 
of textile materials," International Journal of Basic andApplied Chemical Sciences, vol. 2, no. 2, pp. 8-24, 2012.

[34] M. Gorensek, M. Gorjanc, V. Bukosek, K. Janez, P. Jovancic, and M. Darka, "Functionalization of PET fabrics by corona and nano silver," Textile Research Journal, vol. 80, no. 3, pp. 253-262, 2010.

[35] ASTM Designation: E 2149-01 method, "Standard test method for determining the antimicrobial activity of immobilized antimicrobial agents under dynamic contact conditions".

[36] C. C. Chen, C. C. Wang, and J. T. Yeh, "Improvement of odor elimination and anti-bacterial activity of polyester fabrics finished with composite emulsions of nanometer titanium dioxide-silver particles-water-borne polyurethane," Textile Research Journal, vol. 80, no. 4, pp. 291-300, 2010. 

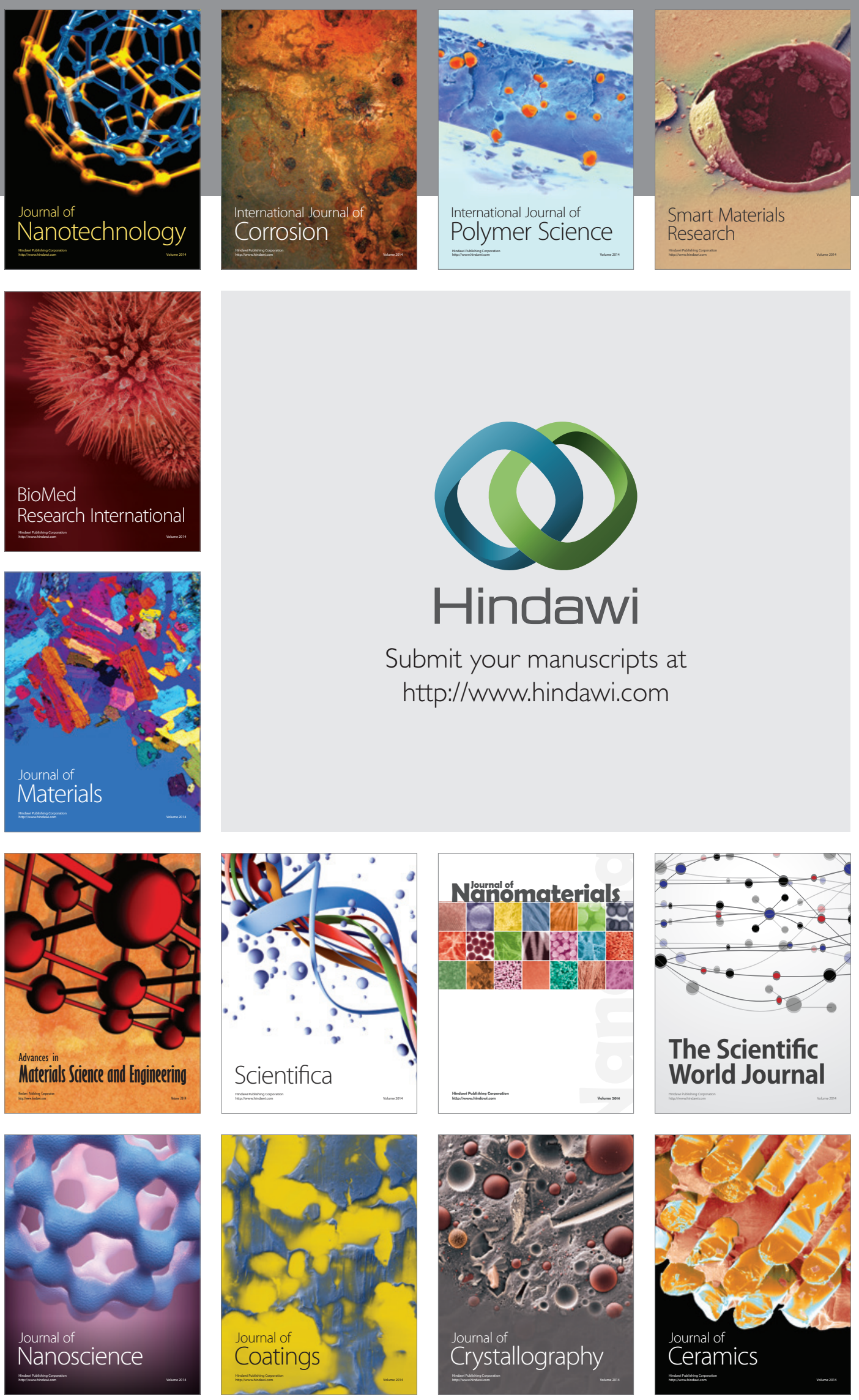

The Scientific World Journal

Submit your manuscripts at

http://www.hindawi.com

\section{World Journal}

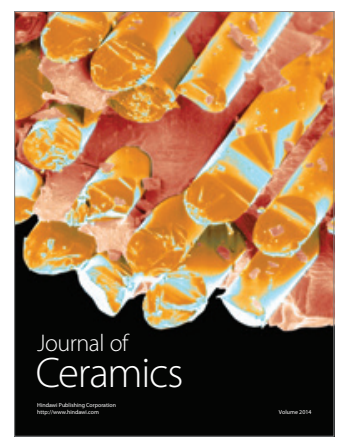

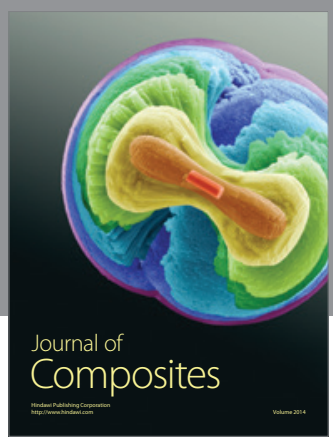
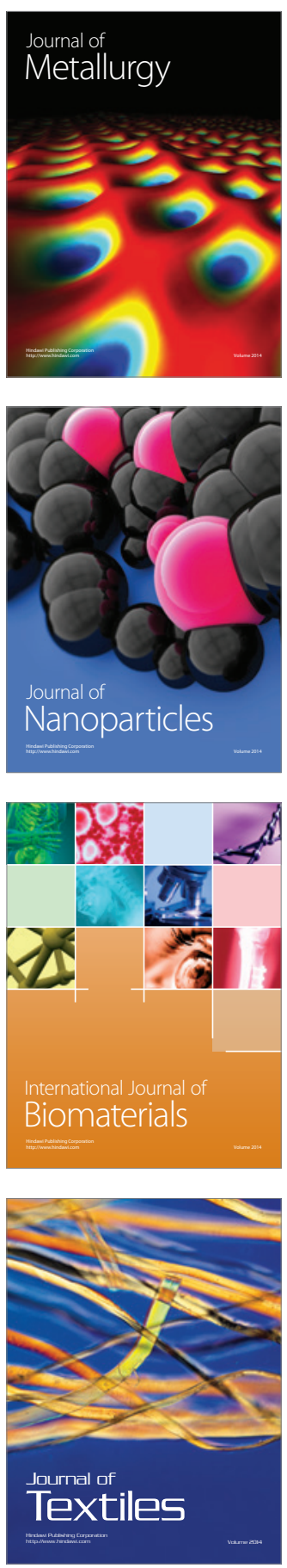